\title{
EPISTEMOLOGIA ENUNCIATIVA NA CLÍNICA FONOAUDIOLÓGICA DO AUTISMO
}

\author{
ENUNCIATIVE EPISTEMOLOGY IN THE \\ PHONOAUDIOLOGICAL CLINIC OF AUTISM
}

\author{
Isabela Barbosa do Rêgo Barros \\ Universidade Católica de Pernambuco, UNICAP, Boa Vista, PE, Brasil \\ Lorena Grace Alves do Vale \\ Universidade Católica de Pernambuco, UNICAP, PE, Brasil
}

\begin{abstract}
Resumo: Propomos discutir os princípios epistemológicos da teoria enunciativa de Benveniste presentes na clínica fonoaudiológica que trata o autismo, a partir de recortes enunciativos oriundos da clínica. As máximas benvenistianas póem o homem no centro da língua/ linguagem e permite-nos perceber o movimento linguístico singular do sujeito diagnosticado com o transtorno, embora o autor não tenha dedicado seus estudos à fala desviante. A clínica, influenciada pelos preceitos teóricos da linguística enunciativa benvenistiana, retoma seu objeto de estudo, a linguagem, pelo víeis daquele que fala, não apenas e tão somente, pelo sintoma.
\end{abstract}

Palavras-chave: Enunciação; língua; linguagem; autismo.

Abstract: We propose to discuss the epistemological principles of Benveniste's enunciative theory present in the speech therapy clinic that deals with autism, based on enunciative clippings from the clinic. The benvenist maxims put man at the center of the language / language and allow us to perceive the singular linguistic movement of the subject diagnosed with the disorder, although the author has not dedicated his studies to deviant speech. The clinic, influenced by the theoretical precepts of benvenistian enunciative linguistics, resumes its object of study, language, through the viability of the one who speaks, not only and only, by the symptom.

Keywords: Enunciation; language; autism.

\section{Introduçáo}

No prefácio não datado da quinta edição da obra Problemas de Linguística Geral I (PLG I), publicada em 2005 no Brasil, é possível ver, em um autor que assina simplesmente com suas iniciais E. B., o reconhecimento de que o estudo e análise da linguagem faz-se por árduos caminhos e que as reflexóes sobre o objeto apenas se mostram eficazes quando apoiadas sobre 
as línguas reais. A simplicidade na assinatura parece se opor à complexidade da leitura da obra benvenisteana. Destacamos no prefácio de Benveniste a referência sobre as línguas reais, para interpretá-la como uma alusão do autor ao terreno da língua(gem) em uso, a fim de justificarmos a maneira singular de enunciação do autista, o que poderia modificar o olhar do fonoaudiólogo sobre o sujeito.

Fundamentamos este artigo na quinta parte do PLG I e do PLG II, segunda edição publicada no Brasil em 2006, ambas grafadas no sumário como $O$ homem na língua, mas tratada por Benveniste em seu prefácio no PLG I como O homem na linguagem e definida, por ele mesmo, pelas formas linguísticas da subjetividade e pelas categorias da pessoa, dos pronomes e do tempo. Elegemos os textos A Natureza dos pronomes (1956), Da subjetividade na linguagem (1958) e $A$ forma e o sentido na linguagem (1966) por apresentarem um autor dedicado à definição de linguagem com destaque dado ao sujeito.

Nosso objetivo aqui é propor discussóes em torno dos princípios epistemológicos da teoria enunciativa de Benveniste presentes na clínica fonoaudiológica que trata o autismo, sustentadas em três grandes temas, a saber: pessoa/não pessoa, semiótico/semântico e aparelho formal da enunciação. Desse modo, defendemos que, a partir das leituras da obra benvenisteana, é possível estabelecer uma clínica que tem seu lugar original na medicina, mas pode ser amparada pela linguagem em seu caráter enunciativo. Então, na primeira parte deste estudo procuramos apresentar aspectos teóricos da enunciaçáo que poderão desaguar em um olhar enunciativo da clínica fonoaudiológica voltada para o atendimento de sujeitos diagnosticados com autismo, a qual se refere a nossa segunda parte.

\section{O legado benvenisteano}

Herdeiro do estruturalismo, Benveniste ressoou as ideias saussureanas, partindo de uma leitura atenta do Curso de Linguística Geral (CLG). O pesquisador resgata de Ferdinand de Saussure (2006) uma linguística da significação, faz referência direta às contribuições saussureanas e trata do problema linguístico inserindo novos conceitos, modificando métodos descritivos, noção de referência e seus consequentes desdobramentos nas dimensôes semióticas e semânticas (NORMAND, 1996; 1997; STUMPF, 2010; NUNES, 2011). 
Em Saussure após meio século, conferência proferida em 1963 na Universidade de Genebra, para marcar as comemoraçôes do cinquentenário da morte de Ferdinand de Saussure e publicada no PLG I, o próprio Benveniste reverencia os feitos de Saussure, dizendo "Saussure é em primeiro lugar e sempre o homem dos fundamentos” (BENVENISTE, 2005, p. 35). Além de um breve apanhado histórico, mencionando o papel fundamental de Saussure nas transformaçóes da ciência linguística em sua época, o autor costura em seus estudos as suas próprias contribuiçôes às consideraçôes do precursor do estruturalismo.

\begin{abstract}
Abarcando com o olhar esse meio século decorrido, podemos dizer que Saussure cumpriu bem o seu destino. Além da sua vida terrena, as suas ideias brilham mais longe do que ele teria podido imaginar, e esse destino póstumo se tornou como uma segunda vida, que se confunde para sempre com a nossa (BENVENISTE, 2005, p. 49, grifo nosso).
\end{abstract}

Trois (2004) destaca que Benveniste busca romper a barreira dos estudos da significação trazendo a subjetividade na língua, que preenche, de forma única, o vazio no interior saussuriano, conservando seus fundamentos e ultrapassando-os. Assim sendo, percebemos que Benveniste não refuta as conjecturas de Saussure, outrossim, propositadamente propóe um incremento alicerçado nela.

Benveniste inicia o texto Da subjetividade na linguagem, publicado em 1958, com um questionamento: "Se a linguagem é, como se diz, instrumento de comunicação, a que deve a ela essa propriedade?" (BENVENISTE, 2005, p. 284). Sem dúvida o autor reconhece que comunicar é inerente à linguagem, porém, faz uma crítica aos estudos behavioristas comentados mais adiante no próprio texto, quando menciona o destaque dado ao caráter comportamental e instrumental da linguagem. Parece que, ao iniciar seu texto com uma reflexão, Benveniste quer nos dizer, e diz, que a linguagem é algo mais além que um instrumento de comunicação. Não é a linguagem que se encontra subordinada à comunicação. No dizer de Benveniste, o inverso torna-se verdadeiro quando percebemos que a realidade da comunicaçáo dá-se por meio da palavra habilitada pela linguagem.

Em uma perspectiva antropológica da linguagem, vide o excerto "não atingimos nunca o homem separado da linguagem e não o vemos nunca inventando-a. [...] A linguagem ensina a própria definição do homem" (BENVENISTE, 2005, p. 285), o autor segue seu texto tentando destituir a linguagem do papel de ferramenta utilizada para comunicar, 
colocando-a na natureza humana, no papel constituinte do sujeito. A perspectiva da linguagem como lugar constituinte do sujeito alicerça nosso olhar ao interrogar a clínica fonoaudiológica do autismo: se a linguagem é um instrumento de comunicação, o que dizer sobre o objeto de estudo da Fonoaudiologia quando está em jogo um sujeito que pode apresentar mutismo, neologismos e ecolalias que dificultariam a comunicação? Seria esse sujeito destituído de linguagem e consequentemente não assumiria seu lugar de partícipe da herança da língua?

Quando nos aproximamos dos textos de Benveniste, principalmente esse de 1958, é possível encontrar no autismo um sujeito linguístico que se constitui de modo singular, posto que a subjetividade na linguagem trata do eu que se constitui na linguagem e pela linguagem; não é, simplesmente, o homem, nem o locutor. Nessas circunstâncias, não estamos nos reportando a um falante, mas a uma condição de existência como sujeito:

\footnotetext{
A consciência de si mesmo só é possível se experimentada por contraste. Eu não emprego $e u$ a não ser dirigindo-me a alguém, que será na minha alocução um tu. Essa condição de diálogo é que é constitutiva da pessoa, pois implica em reciprocidade - que eu me torne $t u$ na alocução daquele que por sua vez se designa por $e u$. [...] A linguagem só é possível porque cada locutor se apresenta como sujeito, remetendo a ele mesmo como eu no seu discurso. Por isso, $e u$ propóe outra pessoa, aquela que, sendo embora exterior a "mim", torna-se o meu eco - ao qual digo tu e que me diz tu (BENVENISTE, 2005, p. 286).
}

O sujeito não se faz no reconhecimento de si como indivíduo, mas na troca de experiências vividas por contraste e complementaridade entre o 'eu' e o 'tu' no exercício da língua e que fundamenta a subjetividade. Benveniste retoma no texto de 1958, Da subjetividade na linguagem, discussóes iniciadas em 1956, no texto $A$ natureza dos pronomes. Nesse, Benveniste destaca os pronomes como fato de linguagem característico da instância do discurso, ou seja, 'eu' e 'tu' resultam da atualização da língua a cada instante único e singular em que ela é posta em ação por um locutor. "[...] A forma 'eu' só tem existência linguística no ato de palavras que a profere" (BENVENISTE, 2005, p. 279). Consequentemente, o 'tu' surge de modo semelhante no discurso como indivíduo alocutado cada vez que há referência ao 'tu'.

Em Benveniste, é possível encontrar destaque aos pronomes 'eu' e 'tu' como formas que não remetem a posiçóes definidas e preestabelecidas no tempo e no espaço, as quais náo precisam estar sempre marcadas no discurso quando não se faz regra no sistema linguístico, a exemplo do português, que 
admite enunciados com sujeito oculto, para que ocorram os movimentos intersubjetivos. Contudo, é preciso que os locutores apresentem-se como 'eu' ou como 'tu' no discurso. Ao lado dos indicadores de tempo e espaço, os pronomes pessoais 'eu' e 'tu' compóem a categoria da dêixis representativa da subjetividade na linguagem.

No entanto, a presença do 'eu' só é permitida pela cessão do lugar do 'eu' do interlocutor em um movimento de troca de posição dos sujeitos na linguagem. Ou melhor, é preciso que o 'tu' reconheça a posição subjetiva de falante do seu interlocutor e ceda seu lugar outrora de locutor, caracterizando a atualizaçáo da língua no discurso, a cada nova tomada de posição durante a enunciaçáo.

Ao tratar da enunciação, as discussôes epistemológicas de Benveniste provocam uma cisão do que já era conhecido na linguística como sistema linguístico, enquanto instância intralinguística. Isso traz para o campo da linguística o sujeito, no momento em que destaca a fala suscitando as categorias de pessoa, espaço e tempo, as quais Benveniste atribuirá o aparelho formal da enunciação, abrindo a possibilidade ao extralinguístico.

[...] este ato de discurso que enuncia eu aparecerá, cada vez que ele é reproduzido, como o mesmo ato para aquele que o entende, mas para aquele que enuncia, é cada vez um ato novo, ainda que repetido mil vezes, porque ele realiza a cada vez a inserção do locutor num momento novo do tempo e numa textura diferente de circunstâncias e de discursos (BENVENISTE, [1965] 2006, p. 68).

Normand (2019) atribui a Benveniste a passagem da noção não questionada na linguística do sujeito falante (o homem) à noçáo explicitamente problemática de sujeito da enunciação ou de enunciaçáo, termo, no entanto, ignorado por Benveniste. É o deslocamento do objeto linguístico que em Saussure centrava-se na língua para um destaque dado à linguagem dentro da linguística, que possibilita os estudos sobre o sujeito na linguística. De acordo com Ferreira Júnior e Cavalcante (2009),

o estudo desenvolvido por Benveniste, que trouxe no escopo da sua teoria (se é que é possível tomá-lo no singular) concepçôes tão caras à Linguística, como o modo de representação do sujeito na estrutura da língua e o processo de enunciação pode revelar sobre o sujeito (JUNIOR; CAVALCANTE, 2009, p. 302).

A noção de enunciação permite a emergência do falante nas línguas e o lugar ao ato de dizer, pois não há língua sem enunciação. A enunciação é 
a única categoria que preenche todas as condiçóes para ser simultaneamente geral e específica, para ser de todas as línguas e de cada uma em particular, para ser de toda humanidade e de cada indivíduo especificamente, uma vez que "a linguagem está de tal forma organizada que permite a cada locutor apropriar-se da língua toda designando-se como eu (BENVENISTE, 2005, p. 288). Neste momento nos deparamos com o universal antropológico, no sentido de conhecimento geral do homem, na medida em que a enunciação está inscrita na condição de todo e qualquer falante, ela é própria do homem (FLORES, 2019).

No texto de 1966, A forma e o sentido na linguagem, dirigido a filósofos, Benveniste inicia criticando o Estruturalismo norte-americano, trazendo Bloomfield como exemplo de desinteresse dos linguistas pelas questóes que envolvem o sentido. Opondo-se a isso, afirma que o caráter primordial da linguagem é significar. E significar é ter um sentido. Para esse autor "o sentido é a noção implicada pelo termo mesmo da língua como conjunto de procedimentos de comunicaçáo identicamente compreendidos por um conjunto de locutores" (BENVENISTE 2006, p. 222, grifo nosso). Ou seja: o critério para determinar se algo significa ou não é estabelecido pelos sujeitos, 'eu' e 'tu' no discurso, em referência a algo no presente da cena enunciativa.

Mais adiante no texto, Benveniste retorna às explicações sobre a significação como vocação original da linguagem em consonâncias com as funçôes da linguagem. $\mathrm{O}$ autor menciona que essas seriam inúmeras e para resumi-las conclui: "[...] bem antes de servir para comunicar, a linguagem serve para viver” (BENVENISTE, 2006, p. 222, grifo nosso). Note o retorno de Benveniste ao tema comunicação, inicialmente apresentado por nós neste artigo no texto Da subjetividade na linguagem publicado em 1958. Parece que, ao lado das consideraçóes sobre a enunciaçáo e a subjetividade na linguagem, o autor marca sua crítica à definiçẫo primeira da linguagem como comunicação.

Esse achado nos é importante, porque algumas consideraçóes ligadas ao autismo tratam o sujeito como desprovido de linguagem, baseado na definição de linguagem como comunicação resultante dos achados de Leo Kanner (1943), psiquiatra infantil que diagnosticou o autismo no ano de 1943 nos EUA. Na ocasião, o contexto linguístico americano era dominado pelos trabalhos de Leonard Bloomfield, teórico do Estruturalismo em sua vertente norte-americana, fortemente influenciada pelo Behaviorismo.

À forma cabe a estrutura ou o arranjo linguístico presente no 
enunciado. É possível pensar quão imprevisível podem ser as manifestaçôes de sentido na língua enquanto definidos podem ser os aspectos da forma, ou seja, os aspectos da significação são fugidios na linguagem.

\section{Por uma clínica enunciativa no autismo}

Embora venham sendo estudados há décadas, desde quando o autismo foi descrito pela primeira vez pelo médico Leo Kanner (1943), os esclarecimentos sobre a linguagem, a língua e a fala do ponto de vista linguístico no autismo parecem ainda não terem findado. Ainda enraizada em um discurso que toma a linguagem como comunicação, a língua como um código e a fala como um veículo, a clínica fonoaudiológica, de um modo geral, segue na expectativa de "normalizar" a fala do autista, muitas vezes sem considerar a singularidade da linguagem e do sujeito submetido ao programa terapêutico. Transformar o singular em regular parece ser o propósito clínico.

Em posição contrária, Surreaux (2006) evidencia que, na clínica, precisamos considerar as manifestaçóes linguageiras como algo inerente ao sujeito e instaurar um ponto de vista singular sob o sintoma da linguagem. A autora propóe instaurar uma concepção de linguagem própria à clínica das patologias da linguagem baseada nas reflexóes saussureanas quanto à língua em uso.

Seguindo as orientações de Surreaux, Barros (2011) sugere, fundamentada nas consideraçóes saussureanas, que, no autismo, a língua comporta-se em um movimento de retorno entre os eixos sintagmático e paradigmático: ora a língua estaria presa ao eixo sintagmático na figura de um discurso ecolálico ${ }^{1}$, ora livre no paradigmático por meio de neologismos ou vocalizaçóes aleatórias. Essa fixação em um dos eixos, segundo a autora, representaria o comportamento autístico de aversão às mudanças sendo exposto na linguagem, uma vez que o autista estaria seguro no discurso já proferido por outro.

Ademais, a autora, fundamentada nas considerações benvenisteanas, procura responder às consideraçóes sobre a linguagem no autismo, apontando que há uma relação enunciativa do sujeito, posto que o autista está na linguagem e faz-se efeito através do uso singular do sistema linguístico.

${ }^{1} \mathrm{~A}$ ecolalia são repetiçóes do discurso ou de partes de um discurso proferido por outrem, efetuadas pelo autista imediatamente após serem ouvidos ou após um certo tempo, aparentando uma ausência de contexto. 
É necessário, completa Barros (2011), que o 'tu', no lugar de interlocutor do autista, reconheça nas produçóes linguísticas desviantes um movimento subjetivo do 'eu' na linguagem.

A partir das consideraçóes das autoras procuramos atestar as bases epistemológicas da teoria enunciativa de Benveniste que norteiam a clínica do autismo, apresentando uma metodologia restrita à promoçáo do uso da linguagem submetido à gramática da língua no atendimento clínico fonoaudiológico. Pensar no que acontece com a linguagem, a língua e o falante, leva-nos a refletir sobre os fundamentos que comportam reflexóes oriundas da interlocuçáo entre a Fonoaudiologia e a Linguística, quando o que está em jogo é a linguagem e o sujeito que sofre pelo efeito de uma condição sintomática. Afinal, deveria ser óbvio o lugar da ciência da linguagem, a Linguística, na clínica cujo objeto é a linguagem.

$\mathrm{Na}$ seção anterior, apresentamos três grandes temas tratados por Benveniste (2005; 2006), nas obras Problemas de Linguística Geral, volumes I e II, que, em nossa concepção, sustentam a clínica fonoaudiológica: pessoa/não pessoa, semiótico/semântico e aparelho formal da enunciaçáo. Aqui, pretendemos, apresentá-los em meio às análises de dois cortes de cenas enunciativas oriundas da clínica e pertencentes a um mesmo corpora de estudos sobre a linguagem no autismo para responder a questão: como os dados epistemológicos da teoria enunciativa de Émile Benveniste circulam na clínica fonoaudiológica do autismo?

Nosso objetivo aqui é propor discussões em torno dos princípios epistemológicos da teoria enunciativa, defendendo que, a partir das leituras da obra benvenisteana, é possível estabelecer uma clínica que tem seu lugar original na medicina, mas pode ser amparada pela linguagem em seu caráter enunciativo.

Concordamos com Cardoso (2010), quando discute, em sua tese de doutorado, o problema de que as áreas que se dedicam às questôes da linguagem na instância clínica dos distúrbios da linguagem não possuem conhecimento integral da linguagem, tampouco pauta sua intervenção levando em consideração os aspectos da condição de enunciador do paciente. Isso posto, acreditamos que a concepção de linguagem do fonoaudiólogo seja tal que possibilite subsidiar uma clínica que evidencie o sintoma como possibilidade de o sujeito enunciar-se.

Uma clínica de base enunciativa, então, constrói-se a partir dos cortes epistemológicos herdeiros da tradição benvenisteana, destacando o papel constitutivo da linguagem ao considerar a importância do sujeito e a sua 
relação com a linguagem. Benveniste (2005), é categórico ao afirmar que o sujeito constitui-se na e pela linguagem. Isso nos deixa seguros para pensar que não importa em que condição estrutural faz-se linguagem - ou seja, se há ou não a obediência do sujeito às regras linguísticas -, mas o exercício da linguagem, a colocação da língua em funcionamento definidora da enunciação é o que deve ser considerado em nome de um sujeito que se faz presente no sintoma.

A clínica atravessada pelo estatuto de pessoa é um espaço onde falar é sempre falar para o outro em uma troca de posiçấo entre o 'eu' e o 'tu' e onde o sujeito refaz-se, tornando-se efeito a cada novo uso da língua. Percebem-se os fundamentos epistemológicos da enunciaçáo norteando a clínica no instante em que os falantes póem-se em uma posição de interlocução. Vejamos as cenas enunciativas a seguir, na qual Estênio ${ }^{2}$, uma criança com 7 anos de idade e com diagnóstico de autismo, está diante de sua fonoaudióloga:

\begin{tabular}{|c|c|c|c|}
\hline & Fonoaudióloga & Criança & Cena enunciativa \\
\hline 1 & & $\begin{array}{l}\text { Eu vi o sapo na beira } \\
\text { do rio de camisa verde }\end{array}$ & $\begin{array}{l}\text { A criança senta na mesa } \\
\text { infantil, pega o dominó, } \\
\text { retira as peças, separa- } \\
\text { as sem uma aparente } \\
\text { categorização e as empilha, } \\
\text { em um movimento } \\
\text { ritmado e estereotipado, } \\
\text { acompanhado da canção } \\
\text { tipicamente infantil. }\end{array}$ \\
\hline 2 & & $\begin{array}{l}\text { Posso guardar? Posso } \\
\text { guardar? }\end{array}$ & $\begin{array}{l}\text { Continua com a atividade } \\
\text { ritmada sem olhar para a } \\
\text { fonoaudióloga. }\end{array}$ \\
\hline 3 & $\begin{array}{c}\text { Pode. Tu queres guardar } \\
\text { o quê? }\end{array}$ & & \\
\hline 4 & & $\begin{array}{l}\text { Pichu, pichu, pichu, } \\
\text { pichu }\end{array}$ & A criança fala baixo. \\
\hline 5 & Que foi? Tu tá feliz é? & & \\
\hline 6 & & UUIIIIIIIII & $\begin{array}{l}3 \text { segundos após o } \\
\text { enunciado da interlocutora, } \\
\text { a criança vocaliza gritando. }\end{array}$ \\
\hline 7 & Que foi Estênio? & & \\
\hline
\end{tabular}

${ }^{2}$ Nome fictício utilizado para preservar a identidade da criança. 


\begin{tabular}{|c|c|c|c|}
\cline { 2 - 4 } \multicolumn{1}{c|}{} & Fonoaudióloga & Criança & Cena enunciativa \\
\hline 8 & & (tchili) AEEE & $\begin{array}{c}\text { Bate com uma peça de } \\
\text { dominó sobre a mesa }\end{array}$ \\
\hline
\end{tabular}

Quadro 1: Ecolalia, neologismos e vocalizaçôes

Fonte: BARROS, 2006, p. 59.

Para uma clínica enunciativa no autismo existir é preciso um entendimento da relaçáo entre sujeitos e linguagem.

\section{AUTISTA - LINGUAGEM - INTERLOCUTOR}

Não foi por acaso que colocamos a linguagem entre sujeitos, uma vez que é na relação intersubjetiva proporcionada pela linguagem que os sujeitos movimentar-se-ấo. Nesse ambiente não se desconsideram quaisquer produçôes linguageiras já que todas comportam a enunciação do sujeito, conforme observamos no discurso da interlocutora da criança em aceitar as produçóes singulares como próprias ao sujeito, em uma tentativa de provocar a circulação da linguagem.

As ecolalias (linhas 1 e 2), o neologismo (linha 4) e as vocalizaçóes (linhas 6 e 8) representam a ação do sujeito que atualiza a língua a cada uso e, desse modo, enuncia-se. Nestes recortes enunciativos observamos o reconhecimento do interlocutor do uso do signo linguístico pelo falante, apesar das combinaçóes singulares efetivadas pela criança não apontarem para um sentido intrínseco a forma linguística utilizada. Ter na clínica fonoaudiológica um espaço para a construção e não para a imposição de sentidos possibilita que entre os sujeitos haja uma relação de parceria para o estabelecimento da linguagem. Nesse aspecto, a comunicaçáo é uma consequência da emergência do sujeito.

Pelo viés enunciativo, encontramos na clínica lugar para firmar a posição de falante do autista. Ou seja, quando a fonoaudióloga se coloca no papel do 'tu' percebe que nas desconstruçôes sintagmáticas há uma ação individual em colocar o sistema linguístico em funcionamento de modo particular e, consequentemente, enunciar-se. Náo estamos falando em entendimento do discurso, mas da condiçáo de sujeito na clínica fonoaudiológica, a partir da qual será possível acreditar em uma saída do isolamento autístico na linguagem, o que já indicará uma evolução do 
quadro clínico. A cada turno discursivo, os locutores apresentam-se ora como 'eu', ora como 'tu', marcando, assim, os movimentos intersubjetivos.

Como afirmou Benveniste (2005, p. 289), “a linguagem é, pois, a possibilidade da subjetividade, pelo fato de conter sempre as formas linguísticas apropriadas à sua expressão; e o discurso provoca a emergência da subjetividade, pelo fato de consistir de instâncias discretas”. A afirmação permite-nos concluir que uma análise linguística-fonoaudiológica pautada apenas no 'erro' e 'acerto' não possibilita a aceitação de uma apropriaçáo da língua pelo locutor quando esta não ocorre de acordo com o padrão linguístico esperado. Perde-se, assim, o reconhecimento de que os efêmeros e discretos deslizes da linguagem que poderão vir a existir comportariam o funcionamento do sujeito.

Ainda sobre o Quadro 1, enfatizamos aqui a cena enunciativa descrita na linha 1 , que apresenta melodia e conversação ritmada. De acordo com Thevarthen e Gratier (2005 apudLAZINIK; COHEN, 2011), as vocalizaçóes são rearranjadas em turnos de falas verbais e elas carregam consigo uma musicalidade única que é tão significativa quanto qualquer palavra. Ora, toda troca intersubjetiva, seja por gestos, olhares, emissão vocal, expressóes faciais ou postura corporal do locutor ao interlocutor, prioriza o conteúdo do que se deseja expressar. Marca-se aí, portanto, a condição de presença da criança na linguagem.

No Quadro 2, a seguir, teremos a oportunidade de observar o papel colaborativo da criança autista ao trazermos uma situação de discurso em que é possível perceber o deslize na linguagem da criança que passa de vocalizaçóes a produçóes espontâneas.

\begin{tabular}{|c|c|c|c|}
\hline & Fonoaudióloga & Criança & Cena Enunciativa \\
\hline 1 & $\begin{array}{c}\text { quer o vento só para você } \\
\text { é Estênio? (40s) }\end{array}$ & & $\begin{array}{l}\text { Na sala de atendimento } \\
\text { fonoaudiológico, a criança } \\
\text { posiciona o ventilador de } \\
\text { mesa colocando a base } \\
\text { voltada para si. }\end{array}$ \\
\hline 2 & & $\begin{array}{l}\text { uuuUUUUIII (vá } \\
\text { embora) fique aí }\end{array}$ & \\
\hline 3 & $\begin{array}{c}\text { você quer que o } \\
\text { ventilador fique aqui } \\
\text { parado? fique aqui } \\
\text { parado venti-lador (3s) } \\
\text { mexa não! }\end{array}$ & & \\
\hline
\end{tabular}


Quadro 2: A linguagem ao som do vento Fonte: Barros (2006, p. 103).

O contexto enunciativo, caracterizado pelos indicadores dêiticos de tempo, espaço e pessoa permite que o interlocutor certifique o papel de locutor de Estênio. Vemos no recorte acima as marcas da linguagem que, mesmo apresentando rigidez da enunciaçáo, podem ser contornadas quando é respeitada a idiossincrasia da criança e seu modo peculiar de constituirse na/pela língua. A vocalização presente na linha 2 aparentemente não se refere à onomatopeia do som do vento produzido pelo ventilador, mas ao movimento gestual de vai e vem das hélices, marcando o lugar do sujeito de forma singular. Lembremos que a fixação por movimento rotatório é uma característica comum ao autismo.

Destacamos da cena enunciativa o papel do interlocutor, que significa o enunciado da criança, trazendo-a à cena, significando suas vocalizaçóes. "[...] Não se pode esquecer que se o locutor, que ascende a sujeito, integra o fenômeno linguístico é também porque há, do outro lado, um interlocutor que participa deste processo" (CARDOSO, 2011, p. 344). Então, admitimos que náo há um distanciamento do sujeito autista da linguagem, desde que haja um interlocutor que lhe seja próximo.

Para Surreaux (2006), a clínica da linguagem deve considerar qualquer formação linguageira como possível, sendo essa escuta diferenciada um potencializador da produção criativa do sujeito. "Se o sujeito é sempre feito de seu próprio dizer, é necessário analisar quais as particularidades dos efeitos que causam uma fala sintomática no dizer daquele que enuncia” (p. 176). Em uma clínica sustentada pela enunciaçáo, um dos primeiros efeitos deveria ser não adjetivar a linguagem: patológica, sintomática, normal, desviante, não-desviante, típica, atípica, mas, sim, verificar a qualidade das relaçôes originadas quando a linguagem é posta em uso.

Barros (2011, p. 56), apoiando-se nos estudos de Benveniste, considera que "o sujeito se constitui pela linguagem, se impóe e se expóe ao fazer uso da língua por meio da fala ou ao fazer uso de outros sinais (gestos, expressóes corporais, figuras...) e firma sua presença, habita a linguagem, tornando-se efeito dela”. Portanto, podemos afirmar que somente o sujeito torna real a linguagem.

Assim como as palavras que voam no vento, uma vez posta em uso, as construçôes linguísticas jamais serão as mesmas, ou seja: a enunciação é 
irrepetível. É assim que uma vocalização, como tantas que podem surgir no discurso de um sujeito autista, a exemplo da que ocorre na linha 2, pode ser tomada como o 'som do vento' e ser inserida no contexto enunciativo, compondo um fantasioso diálogo com o ventilador presente no discurso da fonoaudióloga, a partir da observação do movimento de vai e vem do ventilador de mesa presente no discurso da criança: vá embora, fique aí. Concordamos com Deissler (2014) que,

Há, então, uma urgência de se dar à fala estereotipada uma dimensão que a atribua significado e privilegie a escuta às outras marcas (entonaçóes vocais, gestos e outros) que se apresentam simultaneamente a estereotipia e que acabam sendo apagadas pelos efeitos que a fala sintomática produz no ouvinte (DEISSLER, 2014, p. 27).

Toda relação traz consigo um sentido, de modo que a linguagem no autismo pode ter um sentido de náo-linguagem ou de linguagem sintomática de acordo com a perspectiva epistemológica que ronda o processo terapêutico. Esse é elemento essencial para pensarmos a relação entre um sujeito, que é autista, a linguagem e a clínica.

Que a linguagem significa quer dizer que a significação não é qualquer coisa que lhe seja dada por acréscimo ou, numa medida mais ampla, por uma outra atividade; é de sua própria natureza; se ela não fosse assim, não seria nada (BENVENISTE, 2006, p. 223).

Da mesma forma como foi apresentado no Quadro 1, a linguagem da criança autista na clínica fonoaudiológica de base enunciativa significa algo quando o interlocutor procura construir amarras discursivas que comporão uma possível cadeia dialógica. Os sentidos errantes comportam a história dos sujeitos. As produçóes linguísticas no autismo inovam, marcam, representam e acima de tudo, significam. Os fatos enunciativos evidenciam a emergência do falante, que, por um processo de significação, é responsável

pela operação discursiva. $\mathrm{O}$ conceito de linguagem para Benveniste afirma, entáo, o surgimento da pessoa e sua constituição subjetiva.

Consideramos, em face do exposto, que não conseguimos perceber a fala do autista noutro lugar, que não seja dentro da linguagem. Afinal, os conceitos e as representaçóes dos signos linguísticos encontram-se presentes na fala do autista através das desconstruçôes linguísticas singulares. 


\section{Consideraçóes finais}

Consideramos que a epistemologia científica que subjaz a teoria da linguagem benvenistiana proporciona-nos, dentre várias possibilidades nos desdobramentos da pesquisa em sintoma da linguagem, refletir sobre o sujeito autista numa perspectiva para além do positivismo do fato linguístico em si, mas do conhecimento da origem da experiência linguística do falante. A grande inovação do pensamento de Benveniste particulariza o uso da linguagem como algo típico do humano, além de abrir grande leque de possibilidades para constituir objetos de investigação.

Portanto, dentro de uma gama de perspectivas e linhas distintas de estudo da linguagem enquanto ciência, acreditamos achar no viés enunciativo um norte para a clínica fonoaudiológica do autismo, que oferece condição de possibilidade para fundamentar metodologicamente e teoricamente a nossa prática, compreendendo que o autista organiza sua própria experiência humana de forma singular na linguagem, sendo atravessado socialmente e biologicamente, justificando pois sua natureza humana existencial.

Concluímos que a tentativa de restaurar a homogeneidade ameaçada ou de "normalizar" a fala desviante é um caminho percorrido por muitos fonoaudiólogos, contudo, reiteramos que o compromisso do mesmo deve ser o de buscar fidelidade e compromisso com a singularidade da fala da criança, mesmo que o estranhamento afete ao locutor e o impossibilite, por vezes, de realizar interpretaçáo afetando o circuito enunciativo.

A linguagem dentro de uma clínica, que tem como objeto uma forma singular de organização do sistema linguístico, comporta a enunciação. Trata-se de olhar para a clínica a partir do que falta ou excede na linguagem representada na inscriçáo de cada sujeito em particular.

\section{Referências}

BARROS, Isabela Barbosa do Rêgo Barros. Os ecos da fala na clínica fonoaudiológica. Dissertação de mestrado em Ciências da Linguagem. Recife: UNICAP/PPGCL, 2006. 
saussureano e benvenistiano sobre a posiçáo do autista na linguagem. Tese de doutorado. João Pessoa: UFPB/CCHLA, 2011.

BENVENISTE, Émile. Problemas de linguística geral I. 5. ed. Campinas: Pontes, 2005.

. Problemas de linguística geral II. 2 ed. Campinas: Pontes, 2006.

CARDOSO, Jefferson Lopes. Princípios de análise enunciativa na clínica dos distúrbios de linguagem. Tese de doutorado em teorias do texto e do discurso. Porto Alegre: UFRGS, 2010.

- O distúrbio de linguagem sob uma perspectiva enunciativa.

Cadernos do IL, Porto Alegre, n. 42, p. 339-347, jun. 2011.

DEISSLER, Lorena Grace do Vale. Multilinguismo e Síndrome do X Frágil: uma relaçáo de identificaçáo na/pela língua. Dissertação de mestrado em Ciências da Linguagem. Recife: UNICAP/PPGCL, 2014.

FERREIRA JÚNIOR, José Temístocles; CAVALCANTE, Marianne Carvalho B.; Subjetividade e aquisição da linguagem: por uma abordagem enunciativa. Graphos, João Pessoa, v. 10, n. 2, p. 301-309, 2009.

FLORES, Valdir do Nascimento. Problemas gerais de linguística. Petrópolis: Vozes, 2019.

KANNER, Leo. Autistic Disturbances of Affective Contact. Nervous Child, n. 2, p. 217-250, 1943.

NUNES, Paula Ávila. Émile Benveniste, leitor de Saussure. Cadernos do IL, Porto Alegre, n. 42, p. 51-63, jun. 2011.

NORMAND, Claudine. Os termos da enunciação em Benveniste. In: OLIVEIRA, Sergio Lopes; PARLATO, Erika Maria; RABELLO, Silvana. O falar da linguagem. São Paulo: Lovise, 1996. p. 127-152.

NORMAND, Claudine. Lectures de Benveniste: quelques variantes sur un itinéraire balisé. Linx. Revue des linguistes de l'université Paris $\mathbf{X}$ Nanterre, v. 9, p. 25-37, 1997. Disponível em: <http://journals.openedition. org/linx/964misenlignele03juillet2012>. Acesso em: 19 abr. 2019.

SAUSSURE, Ferdinand. Curso de linguística geral. São Paulo: Cultrix, 2006.

STUMPF, Elisa Marchioro. Saussure e Benveniste: Ultrapassagem ou rompimento? ReVEL, v. 8, n. 14, p. 01-12, 2010.

SURREAUX, Luiza. Milano. Linguagem, sintoma e clínica em clínica de linguagem. Tese de doutorado em Letras. Porto Alegre: PPGL/UFRGS, 2006. 
TROIS, João Fernando de Moraes. O "retorno a Saussure" de Benveniste: a língua como um sistema de enunciação. Letras hoje, Porto Alegre, v. 39, n. 4, p. 33-43, 2004. 